\title{
Effects of a Physical Activity Intervention Program on Nutritional Status and Health-Related Physical Fitness of Thai Older Adults in Bangkok Metropolitan Area, Thailand
}

\author{
Boonlerst Outayanik ${ }^{1}$, Andre Seabra ${ }^{2}$, Edwin Rosenberg ${ }^{3}$ \\ ${ }^{1}$ Department of Physical Education, Kasetsart University, Bangkok, Thailand \\ ${ }^{2}$ Faculty of Sport, University of Porto, Porto, Portugal \\ ${ }^{3}$ Department of Sociology and Social Work, Appalachian State University, North Carolina, USA
}

\section{Email address:}

fedublo@ku.ac.th (B. Outayanik)

\section{To cite this article:}

Boonlerst Outayanik, Andre Seabra, Edwin Rosenberg. Effects of a Physical Activity Intervention Program on Nutritional Status and HealthRelated Physical Fitness of Thai Older Adults in Bangkok Metropolitan Area, Thailand. American Journal of Sports Science.

Vol. 6, No. 1, 2018, pp. 12-19. doi: 10.11648/j.ajss.20180601.13

Received: November 1, 2017; Accepted: December 7, 2017; Published: January 31, 2018

\begin{abstract}
Aging is frequently associated with a decrease in physical activity levels and consequently a decline in physical fitness, which may contribute to the development of osteoporosis, bone fractures, cardiovascular disease, metabolic syndrome and cognitive impairment. This study sought to examine the effects of an 8 -week physical activity intervention program on nutritional status and health-related physical fitness among Thai older adults. Thirty five healthy elder volunteers in Bangkok city and metropolitan area (aged 61-78 years) completed an 8-week physical activity intervention that comprises a nine matrices exercise (NME) program (5 sessions per week of 30-60 minutes). Measurements were taken at baseline and after 8 weeks, and included height, weight, body mass index (BMI), blood pressure and health-related physical fitness tests (6-minute walk, chair sit-and-reach, arm curl, back scratch, chair stand and 8-ft up and go). Statistical analysis included descriptive statistics and Pair sample t-test. The results found over an 8-week intervention study, participants significantly improved their weight (pre: $57.4 \pm 9.2$; post: $56.7 \pm 9.0, \mathrm{P}<0.003$ ), BMI (pre: $22.40 \pm 0.5$; post: $21.98 \pm 0.5, \mathrm{P}<0.001$,), cardiorespiratory fitness (pre: $447.9 \pm 38.1$; post: $501.0 \pm 47.0, \mathrm{p}=0.000$ ), arm curl (pre: $15.8 \pm 2.9$; post: $22.3 \pm 3.8, \mathrm{p}=0.000$ ) and leg squat (pre: $13.4 \pm 1.7$; post: $19.5 \pm 3.6, \mathrm{p}=0.000$ ) muscular strength, shoulder (pre: $0.4 \pm 7.6$; post: $1.9 \pm 7.9, \mathrm{p}=0.024$ ) and lower back (pre: $-0.8 \pm 10.5$; post: $4.2 \pm 9.0, \mathrm{p}=0.000$ ) flexibility and agility and balance (pre: $8.2 \pm 0.5$; post: $7.9 \pm 0.6, \mathrm{p}=0.000$ ). Blood pressure did not change significantly during the study period $(\mathrm{p}>0.05)$. This study demonstrated an 8-week NME program represents an effective strategy for improving nutritional status and health-related physical fitness of Thai older adults in Bangkok city and metropolitan area.
\end{abstract}

Keywords: Physical Fitness, Nine Matrix Exercise, Health, Thai Aging

\section{Introduction}

Aging can be defined as a progress decline in the ability of an organism to resist stress, damages, and disease [1] and chronological aging is associated with an increased risk of chronic conditions and diseases such as cognitive impairment, cardiovascular disease and metabolic syndrome [2]. Moreover, aging is frequently associated with a decrease in physical activity levels and consequently a decline in physical fitness, which may contribute to the development of coronary heart disease, heart attacks, diabetes, hypertension, obesity, osteoporosis and bone fractures and different kinds of cancer [3, 4]. United States department of health and human services refers that the promotion of regular and daily physical activity is a good strategy to prevent the onset of age-related diseases and disabilities and the risk of many adverse health outcomes and disability conditions [5]. Also, the important factor for preventing the lack of healthy conditions in the elderly is reinforcing physical fitness by promoting physical activity.

Physical fitness is the ability to perform occupational, recreational and daily activities without becoming undue 
fatigued that include musculoskeletal fitness, cardiorespiratory endurance, flexibility, balance, body weight and body composition [6]. A major problem of the older population is physical inactivity and negative lifestyle seriously threatens health and hastens the deterioration rate of human body [7]. The American college of sports medicine recommends that the exercise in the older adults should include aerobic, muscle strengthening and flexibility exercises and in individuals who are at risk for falling or mobility impairment should also include specific exercises to improve balance in addition to the other component of health-related physical fitness [8]. In fact, walking, for example is an excellent form of physical activity for older adults because it is familiar, cheap, safe, easy, convenient and can be performed in social setting (i.e., group walks) [9]. However, older adults may experience difficulty in walking in unfavorable weather conditions such as rain, wind, cold, or heat waves as in Asian countries. Furthermore, the fear of injury, disease, accident, and crime may prevent them walking outdoors [10-12].

Considering that elderly Thai people face these situations in daily life, we attempted to use an innovative physical activity program (nine matrices exercise-NME) that can easily be performed indoors, composed of movements similar to walking [13]. The NME program was developed by Krabuanrat [13] and is based on stepping on a thin mat where several step patterns have been created, which must be followed by participants. This program has the purpose to improve reaction on learning, sensory neuron function, coordination between neuromuscular system and muscle function and stimulate reaction time to practice movement skill [13]. The efficacy of a NME program on health and physical fitness of children and young and older adults has been recently investigated [13-16]. Results suggested that a NME program has beneficial effects on reduction of stress, improvement of movement skill and health of children and youth, increased agility and speed for athletes and also developing agility in soldiers too. For older adults, NME has a clearly beneficial effect in aerobic fitness and balance and agility, but there is no academic evidence that NME has a beneficial effect on strength and flexibility. However, healthrelated physical fitness results were not assessed in elderly people. Therefore, the purpose of this study was to investigate the effects of an 8-week NME program on the nutritional status and physical fitness of Thai elderly people. It was hypothesized that the systematic practice of NME program would have a significant effect in improving nutritional status and physical fitness. The main purpose of this study was to examine the effects of an 8-week NME program on nutritional status and health-related physical fitness among Thai older adults in Bangkok city and metropolitan area.

\section{Materials and Methods}

\subsection{Materials}

Thirty five healthy Thai elderly volunteers in Bangkok city and metropolitan area (aged 61-78 years) completed an 8week physical activity intervention that comprise a nine matrices exercise program (5 sessions per week of 30-60 minutes). Participants were recruited via advertisements at the elder care center in Bangkok city and metropolitan area, Thailand. Medical screening was performed before the start of the intervention period. Participants with medical conditions that would limit their ability to participate in NME program (e.g. registered blindness, severe hearing impairment, uncontrolled hypertension or diabetes, symptomatic cardiorespiratory disease, severe renal or hepatic disease, uncontrolled epilepsy, progressive neurological disease and chronic disabling arthritis) were excluded. Subjects who had participated in a structured physical activity program, for at least 2 years prior to the study were also excluded. The study was approved by the ethics committee of the Kasetsart University. After explaining the aims of the study and making aware of the procedures, including any risks, discomfort, and benefits to the participants, informed consent was obtained. Study participation was voluntary; the participants were free to withdraw at any time; all of the participants completed the study.

\subsection{Methods}

\subsubsection{Nine Matrices Exercise Program (NME)}

The NME program was developed by Krabuanrat [13] with the purpose of improving learning, sensory neuron function, coordination between neuromuscular system and muscle function and to stimulate reaction time to practice movement skill. The NME program emphasizes on nine matrices consisting of stretching, aerobic moving, and body weight training (see Figures 3). The sequences of the NME program were organized by difficulty level and participants were instructed to step on the nine square plate according to the pattern that the supervisor had shown by starting from the simple to the more difficult patterns. To change the pattern, it was required that participants had learned the previous pattern, having completed it twice properly. This NMR program consists of slow walk and brisk walk in different directions and sequences on the nine matrices square performing 12 moving steps: step 1. forward and backward; step 2. left and right side; step 3. "X"; step 4. square; step 5. "V"; step 6. tri- angle; step 7. double inverted triangle; step 8. stair; step 9. cross; step 10. diagonal; step 11. zig zag; and step 12. row step.

The NME was performed five times a week (Monday to Friday) for 30-60 minutes each session in the afternoon (04:00 pm to 05:00 pm). Each session included 5 minutes of warm-up (stretching, body weight training and balancing exercises), 30-40 minutes of moving on the nine square plate switch stepping up on the box which was 1-3 inches high, and 5-15 minutes of cool-down (stretching exercises). The simplified 12-form nine square movements and 15 stretching exercise forms were used in this study. Stretching exercises have the purpose to improve upper and lower limb flexibility and applied the principle of full range of motion. Static 
stretching techniques were used, which gradually lengthen a muscle to an elongated position (point of the mild discomfort), which were held for a period of 8-20 seconds.
During the sessions, the instructor constantly monitored the older adults and corrected their body positions, joint angles, direction of movement, form- to-form transitions.

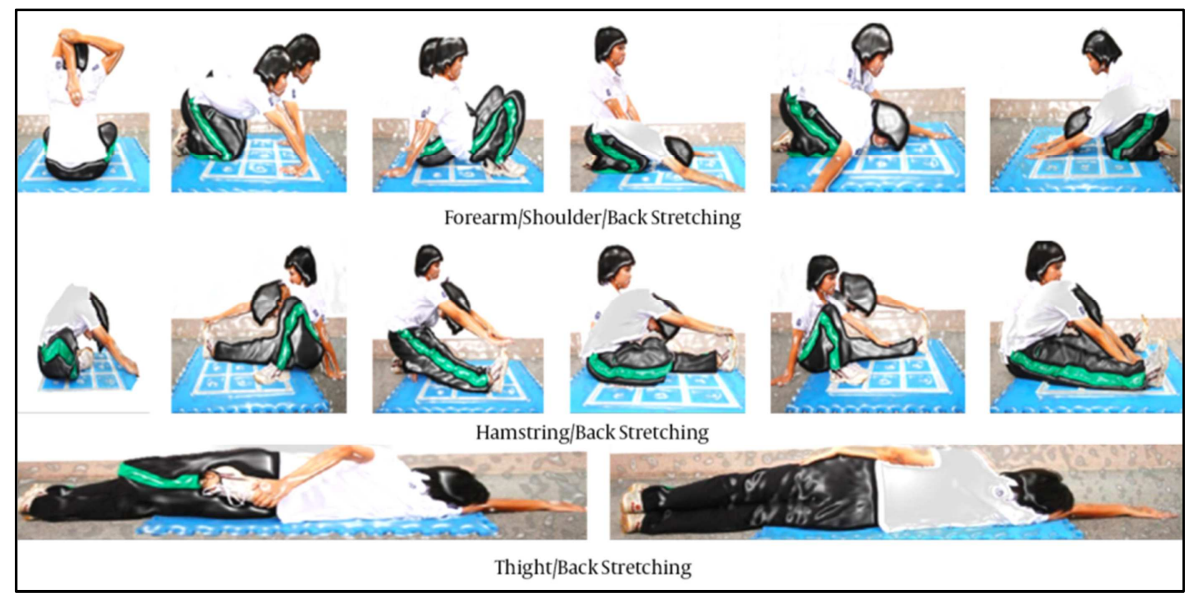

Figure 1. Stretching Exercise on the Plate in NME Program.

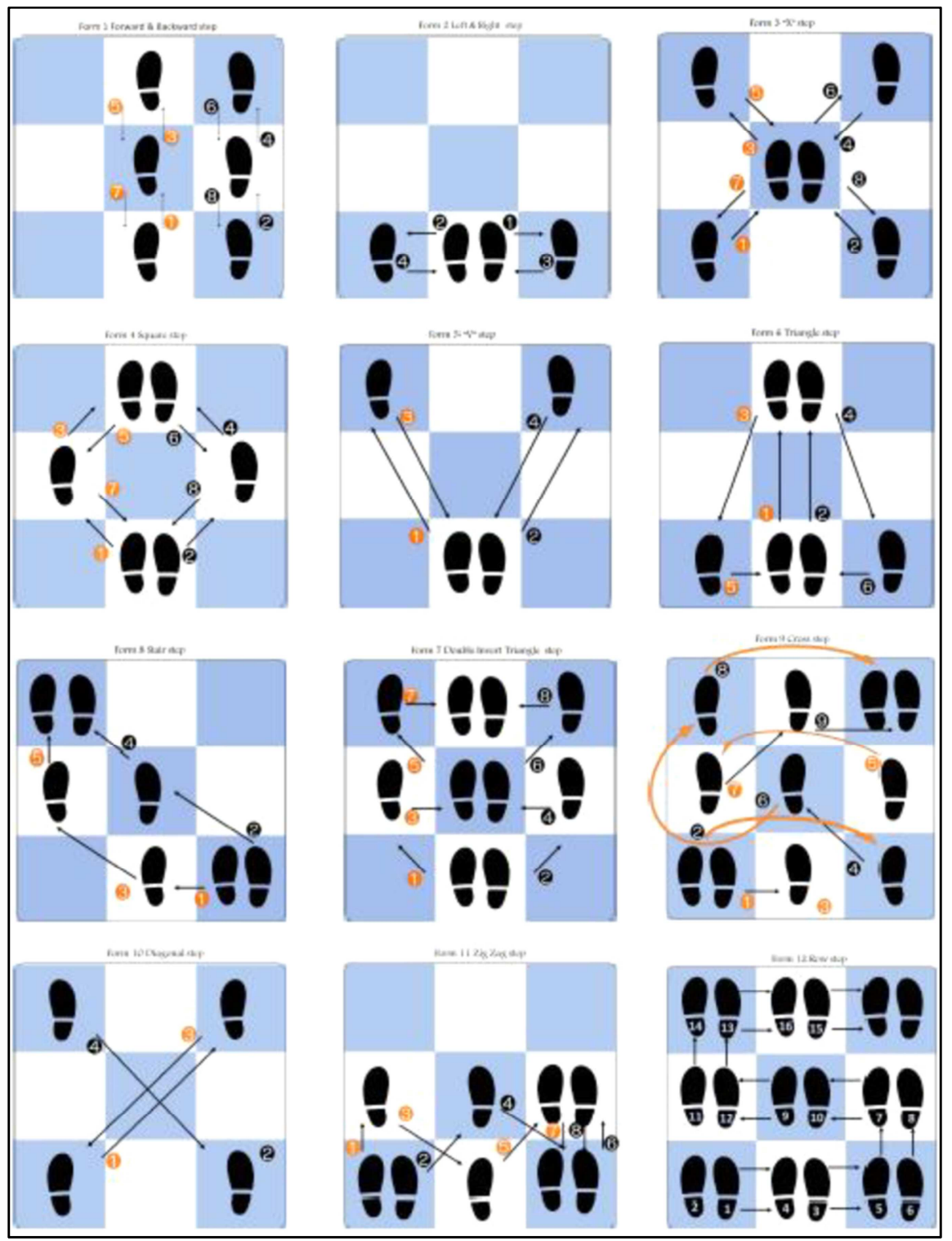

Figure 2. Aerobic Movement on NME Plate. 


\subsubsection{Anthropometry}

Height and body mass were recorded using a portable stadiometer and balance weighing scales, respectively. Subjects were weighed barefoot wearing light clothing. Body mass index (BMI) was calculated using standard formula: body mass $(\mathrm{kg}) /$ height $^{2}(\mathrm{~m})$.

\subsubsection{Blood Pressure}

After being at rest for fifteen minutes, resting blood pressure
(BP) and heart rate (HR) were measured by a digital sphygmomanometer (Omron IA2) in supine position in the right upper limb. The average of three measurements for systolic (SBP) and diastolic (DBP) blood pressure, and HR were entered as data. BP measurements were recorded at least 8 hours after intake of relevant antihypertensive medication. The measurements were performed between 8:00 am and 16:00 am in a quiet, temperature controlled room, by the same investigator.

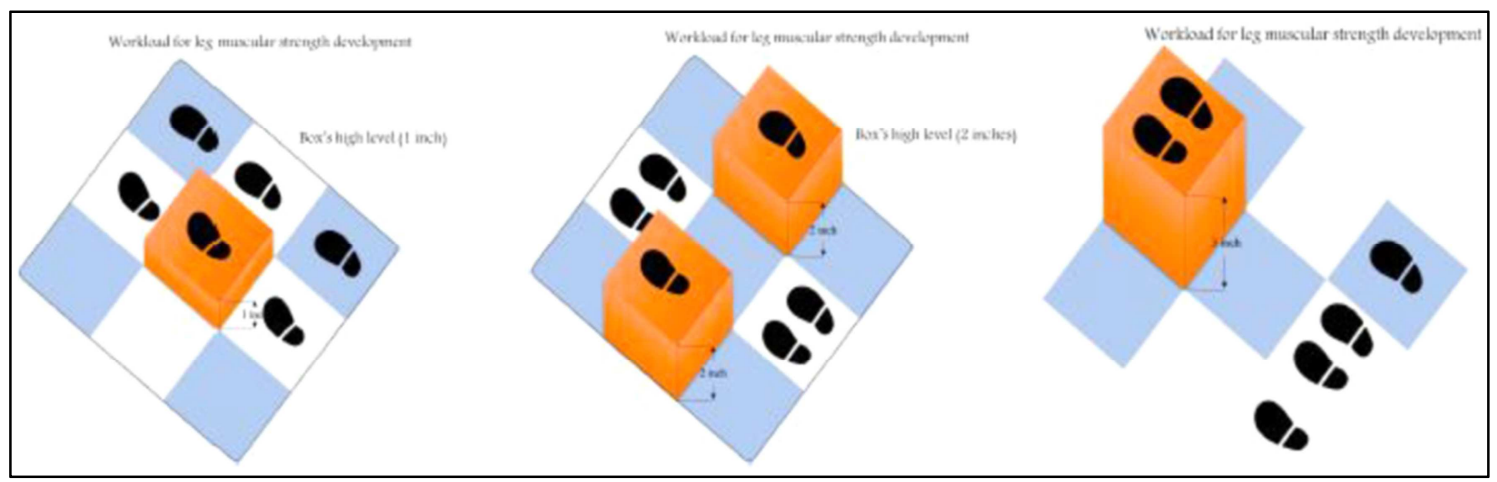

Figure 3. Body Weight Training on 1 - 3 Inches High Box Workload.

\subsubsection{Health-Related Physical Fitness}

The Senior Fitness Test proposed by Rikli and Jones [17] was used to assess health-related physical fitness. This battery consists of 6 assessment items, designed and validated $(0.77 \leq \mathrm{r} \leq 0.83)$ to assess the physiological parameters that support physical functionality and mobility in older adults [17]. These tests included aerobic endurance, arm and leg strength and endurance, chair sit-and-reach flexibility and agility and balance. Aerobic endurance was assessed by 6 -minute walk test. Participants were asked to walk as fast as possible for 6 minutes for 50 yards $(45.47$ meters) with verbal encouragement given at 30 -second intervals. The score was the number of yards walked in 6 minutes. Upper-body strength was assessed by arm curl test which was performed by holding a $5 \mathrm{lbs}$. hand weight. (2.27 $\mathrm{kg}$ ) for women and $8 \mathrm{lbs}$. (3.63 kg) for men, and assess the number of biceps curls that can be completed in 30 seconds holding a hand weight. Lower-body strength was assessed by chair stand test. Participants were asked to performed full stands and sits on a 43-cm-high. The score corresponds to the number of full stands from a seated position that can be completed in 30 seconds with arms folded across chest. Upper-body (shoulder) flexibility was assessed by back scratch test that performed by one hand reaching over the shoulder and one up the middle of the back and measuring the number of inches (centimeters) between the extended middle fingers (plus or minus). Lower-body flexibility was assessed by chair sit-and-reach test. The participants sat on the edge of a chair (placed against a wall for safety). One foot must remain flat on the floor. The other leg is extended forward with the knee straight, heel on the floor, and ankle bent at $90^{\circ}$. One hand was placed on top of the other with tips of the middle fingers even. The distance was measured between the tip of the fingertips and the toes. If the fingertips touch the toes, then the score is zero. If they do not touch, the distance between the fingers and the toes is measured (a negative score), if they overlap, the amount is measured (a positive score). The agility/dynamic balance was assessed by foot up-and-go test in which the participant gets up from a seated position and walks straight way 8 feet $(2.44$ meters) and turn-returns to seated position, and the performance is assessed from the number of seconds required to get up and return to seated position. All the physical fitness tests showed a high test-retest reliability $(\mathrm{r}>0.80)$.

\subsubsection{Testing}

Baseline and after 8-weeks intervention testing occurred at the first week of September 2016 and the first week of November 2016, respectively. Each participant was tested twice within a 1week period. Interview, anthropometry and blood pressure were measured during an initial visit. Healthrelated physical fitness tests were assessed during a second visit. Assessments were done under similar conditions and at approximately the same time of the day to minimize potential diurnal variation in measured variables. Prior to testing health-related physical fitness tests, the participants performed an 8 - 10 minutes warm- up consisting of jogging and stretching exercises, as well as familiarization trials of each test.

\subsubsection{Measurement Variability}

The reliability of the measurements was determined by the technical error of measurement for anthropometry $(0.30 \mathrm{~cm}$ for height; $0.20 \mathrm{~kg}$ for weight), while the inter- class correlation coefficient was used for blood pressure and health-related physical fitness tests $(0.90$ for aerobic endurance; 0.95 for arm and leg strength and endurance; 0.97 
for chair sit-and-reach flexibility; and 0.88 for agility and balance).

\subsubsection{Statistical Analysis}

Descriptive statistics (means and standard deviations) were calculated at baseline and after 8-weeks. The effect of the NME intervention program was evaluated with the Pair sample t-test. The significance level in all analyses was set at 0.05 . Statistical analyses were conducted using SPSS version 21.0.

\section{Results and Discussion}

\subsection{Results}

Characteristics of the study participants are detailed in Table 1 . The sample included more females $(25,71.4 \%)$ than males $(10,28.6 \%)$. In males, the percentages of high school, undergraduate and graduate were $20 \%, 60 \%$ and $20 \%$, respectively. For females, the percentages of undergraduate and graduate were $20 \%, 57.1 \%$ and $22.9 \%$, respectively. Changes in anthropometric, nutritional status, blood pressure and physical fitness are shown in Table 2. After 8-weeks of NMR training, study participants improved significantly their weight (pre: $57.4 \pm 9.2$; post: $56.7 \pm 9.0, \mathrm{P}<0.003$ ), BMI (pre: $22.40 \pm 0.5$; post: $21.98 \pm 0.5, \quad \mathrm{P}<0.001$,), cardiorespiratory fitness (pre: $447.9 \pm 38.1$; post: $501.0 \pm 47.0, \mathrm{p}=0.000$ ), arm curl (pre: $15.8 \pm 2.9$; post: $22.3 \pm 3.8, \mathrm{p}=0.000$ ) and leg squat (pre: $13.4 \pm 1.7$; post: $19.5 \pm 3.6, \mathrm{p}=0.000$ ) muscular strength, shoulder (pre: $0.4 \pm 7.6$; post: $1.9 \pm 7.9, \mathrm{p}=0.024$ ) and lower back (pre: $-0.8 \pm 10.5$; post: $4.2 \pm 9.0, \mathrm{p}=0.000)$ flexibility and agility and balance (pre: $8.2 \pm 0.5$; post: $7.9 \pm 0.6, \mathrm{p}=0.000$ ). Blood pressure did not change significantly during the study period $(\mathrm{P}>0.05)$.

Table 1. Characteristics of study participant.

\begin{tabular}{llll}
\hline & Male & Female & Total \\
\hline Participant & $10(28.6 \%)$ & $25(73.4 \%)$ & $35(100 \%)$ \\
Age range (years) & $61-78$ & $61-77$ & $61-78$ \\
Mean age & 68.0 & 63.7 & 64.9 \\
Education & & & \\
High school & $2(20 \%)$ & $5(20.0 \%)$ & $7(20 \%)$ \\
Undergraduate & $6(60 \%)$ & $14(56.0 \%)$ & $20(57.1 \%)$ \\
Graduate & $2(20 \%)$ & $6(24.0 \%)$ & $8(22.9 \%)$ \\
\hline
\end{tabular}

Table 2. Anthropometric, nutritional status, blood pressure and physical fitness characteristics at baseline and after 8 weeks in the study participants.

\begin{tabular}{lllll}
\hline & Baseline & Post & T & Sig \\
\hline Weight $(\mathrm{kg})$ & $57.4 \pm 9.2$ & $56.7 \pm 9.0$ & 2.04 & $0.024^{*}$ \\
Height $(\mathrm{cm})$ & $156.9 \pm 28.1$ & ---- &.-- & $0.000^{* *}$ \\
Body mass index $\left(\mathrm{kg} / \mathrm{m}^{2}\right)$ & $22.40 \pm 0.5$ & $21.98 \pm 0.5$ & 6.19 & $0.001^{* *}$ \\
Resting heart rate $(\mathrm{bts} / \mathrm{min})$ & $76.9 \pm 6.1$ & $73.4 \pm 5.2$ & 3.76 & 0.890 \\
Blood pressure & & & & \\
Systolic (mmHg) & $128.7 \pm 19.1$ & $128.5 \pm 19.7$ & 0.14 & 0.180 \\
Diastolic (mmHg) & $71.7 \pm 7.2$ & $72.9 \pm 4.4$ & -1.37 & $0.000^{* *}$ \\
Aerobic endurance (m) & $447.9 \pm 38.1$ & $501.0 \pm 47.0$ & -5.12 & $0.000^{* *}$ \\
Muscular strength (time) & & & $0.000^{* *}$ \\
Arm curl & $15.8 \pm 2.9$ & $22.3 \pm 3.8$ & -9.31 & \\
Leg squat & $13.4 \pm 1.7$ & $19.5 \pm 3.6$ & -9.87 & $0.024^{*}$ \\
Flexibility (cm) & & & -2.05 & $0.000^{* *}$ \\
Shoulder & $0.4 \pm 7.6$ & $1.9 \pm 07.9$ & -4.36 & $0.000^{* *}$ \\
Lower back \& hamstring & $-0.8 \pm 10.5$ & $4.2 \pm 9.0$ & 5.83 & \\
Agility \& balance (sec) & $8 . .2 \pm 0.5$ & $7.9 \pm 0.6$ & & \\
\hline
\end{tabular}

Sig. $\left(\mathrm{P}<.05^{*}, \mathrm{P}<.01^{* *}\right)$

\subsection{Discussion}

This exploratory study examined the effectiveness of a relatively short-term period ( 8 weeks) of NME program training on nutritional status, blood pressure and physical fitness of healthy, sedentary Thai older adults. This NME program was applied from a nine square movement exercise established for developing a learning program for children based on the belief that movements of hands on a ninesquared model can help develop the brain cell and the cognitive function of the children [13]. The tradition nine square model has existed for at least 10 years and is becoming popular in Thailand and can have significant benefits in improving the health-related physical fitness of older adults [14].

This study found significant increases in muscular strength, flexibility, cardiorespiratory endurance and agility and balance after the 8-week NME program training suggesting that NME training has a potential effect protecting participants against functional declines associated with age. However, despite a trend toward modestly reduced resting $\mathrm{HR}$, BP, and BMI, no significant changes were observed after the 8-week NME program intervention.

\subsubsection{Strength, Agility/Balance Dimension}

Sarcopenia, characterized by the degenerative loss of skeletal muscle mass along with a reduction in muscle tissue quality and muscle function associated with aging, is well documented [18]. Evidence suggests that this age- related muscular atrophy and weakness can act as a predisposing factor for many of the pathological processes associated with an increased risk of morbidity and mortality of older persons [19]. Impairments in muscle function may also predispose elderly subjects to functional limitations [20]. This study shows that NME intervention offers potential benefits to the elderly in terms of muscle strength and other physical 
function. Muscular strength improvement was evidenced in upper and lower body strength. Previous studies have showed similar results combining different modes of exercise, with great results increasing both upper-and lower-limb muscular strength [21, 22]. In addition, our data is consistent with results of another study that showed benefits of squarestepping exercise with respect to improve muscular strength of lower extremely in the older adults [10-12]. Also, other previous studies found that the older adults had significantly increased muscle strength and endurance $(\mathrm{P}<0.05)$ after the 12 weeks of 9 square table aerobic exercise [15]. Furthermore, there were significant improvements in 8-fit upand-go, which is a demonstration of agility/dynamic balance that is related with lower limb muscle strength [23]. In fact, Ryushi et al. [24] demonstrated that better balance was due to rises in muscular strength in older adults. Thus, it seems reasonable to believe that these Thai elderly adults significantly improved the performance of tasks dependent on muscle strength (e.g. sitting and rising from a chair, rapid movements, and quick changes in direction), as reported in previous studies where the participants improved their maximum strength $[10-12,25]$. The improvements in agility/dynamic balance support the concept that Thai older adults are able to improve agility and balance by NME intervention. These results are in agreement with a prior study that studied an 8-week NME in Thai older adults [14]. Moreover, [16] showed significant improvements in agility after the 4,8 weeks of matrix of nine square training as well as the balance of children with cerebral palsy. The reduction in 8-ft up-and-go time, after 8 weeks of NME seems to be of importance given its great relationship with balance and functional capacity that are directly related to the predisposition for falling [17]. Probably, besides the improvements in lower muscle strength, the specific balance activities involved in NME may possibly have stimulated additional benefits. The ACSM [26] emphasizes in its guidelines that balance must always be encouraged in the practice of different types of physical activity, but it is also important to offer activities that might stimulate, directly, balance in seniors.

\subsubsection{Flexibility Dimension}

Present findings suggest that stretching exercise on nine square plate in the NME program training significantly improve shoulder flexibility and lower back and hamstring flexibility. The increased of ROM can most likely be attributed to the static stretching which is most commonly advised as a method for increasing flexibility [27]. The maintenance and development of levels of flexibility closely related to strength and balance are important components of a general health enhancement program during the aging process [28] and decrements in joint ROM with age and established links among poor flexibility, mobility, and physical independence [29-31]. The increase of ROM resulting from prolonged stretching, as in our study, is most likely due to an increase in length of both connective and muscle tissue [32]. Increased connective tissue length can occur due to its property of plastic elongation [33] and increased muscle length can occur through the addition of sarcomeres to the ends of muscle fibers [30, 32, 34]. This study shows that practitioners of stretching exercise on the nine square plate in NME program for 8 weeks possessed better shoulder and lower and hamstring flexibility than they experienced during their previous sedentary lifestyles. Studies have shown both significant positive and no significant effects of exercise on the range of motion of joints in older adults, depending on the duration of the program, sample size, rate of attrition, measurement technique and the training protocol $[35,36]$. The results of the present study demonstrated that Thai older adults were able to gain significant upper and lower body range of motion after 8weeks NME intervention. A stretching component targeting the major muscle groups and performed in all training sessions might have been the primary reason for improved flexibility scores in our study.

\subsubsection{Aerobic Endurance Dimension}

Cardiorespiratory fitness, as measured by 6-minute walk test is defined as the ability to perform large muscle, dynamic, moderate to high intensity exercise for pro- longed periods of time. The results demonstrated that this NME intervention improved cardiorespiratory fitness. In the same way, [37] founded significant increases in cardiorespiratory fitness after 12 weeks of 9-square-table aerobic exercise training. American college of sports medicine recommended aerobic exercise training of sufficient intensity $(60 \%$ of pre-training $\mathrm{VO} 2 \mathrm{max}$ ), frequency, and length (3 d-wk-1 for $16 \mathrm{wk}$ ) in order to VO2max [8]. Taking into account our NME program, specifically its short duration and intensity, we believe that the success of its performance is also dependent on peripheral adaptation, particularly the power and muscular strength of the lower limbs [38]. Thus, the significant improvements in aerobic fitness can be, once more, attributed to increases muscular endurance resulting from the NME program training.

\subsubsection{Body Mass Index and Blood Pressure Dimension}

Finally, the present training protocol improved not only Thai elders' functional capacity but also nutritional status, measured by BMI. These results are consistent with another study where the BMI of older adults significantly declines that after 8 weeks of Thai dance on nine channels table [37]. The results from body composition in our study showed that older subjects were able to achieve a decrease in BMI after 8 weeks of training (5 times/day), enhance at the same time their strength, balance and cardiorespiratory fitness, underlining the importance for older people to participate in regular training for their health, functionality and quality of life [38]. However, in the present study, NME did not have a significant effect on systolic and diastolic blood pressure. Less population in NME intervention program may have influenced the results to improve systolic and diastolic blood pressure. This mean that a sufficient number of patients completed the study according to the power calculation. 


\section{Conclusion}

An 8-week NME program was successful in improving physical fitness of Thai elderly people. These findings are promising and provide support to public health authorities to develop effective, feasible, safe and low-cost physical activity programs to improve elderly physical fitness. In addition, these findings highlight the need for further research in the context of replication and potential translation into more pronounced benefits in longer-term and largerscale studies. However, the limitations of this study include lack of a control group and the consequent lack of generalizability to confirm the valuable of the NME program to the older adults. However, the relative magnitude and consistency of the observed changes support their validity and argue for their replication in future research. Despite these limitations non-randomization of the present, it is important to highlight the uniqueness of the study, as there are no reports in the literature observing the effect of NME sequences alone on functional fitness. In this context, our study proposed a new form of exercise for Thai older adults as an alternative physical activity that would meet the objectives of current recommendations to improve and maintain physical fitness and health.

\section{References}

[1] Bouchard C, Blair SN, Haskell WL. Why study physical activity and health. Physical activity and health. 2007;1:3-20.

[2] Wang CY, Haskell WL, Farrell SW, Lamonte MJ, Blair SN, Curtin LR, et al. Cardiorespiratory fitness levels among US adults 20-49 years of age: findings from the 1999-2004 National Health and Nutrition Examination Survey. $\mathrm{Am} \mathrm{J}$ Epidemiol. 2010;171(4):426-35. doi: 10.1093/aje/kwp412. [PubMed: 20080809].

[3] Meijer EP, Westerterp KR, Verstappen FT. Effect of exercise training on total daily physical activity in elderly humans. Eur J Appl Physiol Oc- cup Physiol. 1999;80(1):16-21. doi: 10.1007/s004210050552. [PubMed: 10367718].

[4] Thygerson A. L., Larson K. L. Fit to be Well. London: Jones and Bartlett Publishers; 2006.

[5] US Department of Health and Human Service. Physical activity guideline for American 2009. Available from: http://www.health. gov/paguideline.

[6] Heyward VH. Advanced Fitness Assessment and Exercise Prescription. Human Kinetics; 2010.

[7] Hoeger WWK, Hoeger SA. Principle and labs for physical fitness. Belmont: Wadsworth; 2012.

[8] American College of Sports M, Chodzko-Zajko WJ, Proctor DN, Fiatarone Singh MA, Minson CT, Nigg CR, et al. American College of Sports Medicine position stand. Exercise and physical activity for older adults. Med Sci Sports Exerc. 2009;41(7):1510-30. doi: 10.1249/MSS.0b013e3181a0c95c. [PubMed: 19516148].

[9] Rowe JW, Kahn RL. Successful aging. NY: Pantheon/Random House; 1998.
[10] Shigematsu R, Okura T. A novel exercise for improving lower- extremity functional fitness in the elderly. Aging Clin Exp Res. 2006;18(3):242-8. [PubMed: 16804371].

[11] Shigematsu R, Okura T, Nakagaichi M, Tanaka K, Sakai T, Kitazumi S, et al. Square-stepping exercise and fall risk factors in older adults: a single-blind, randomized controlled trial. J Gerontol A Biol Sci Med Sci. 2008;63(1):76-82. [PubMed: 18245764].

[12] Shigematsu R, Okura T, Sakai T, Rantanen T. Squarestepping exercise versus strength and balance training for fall risk factors. Aging Clin Exp Res. 2008;20(1):19-24. [PubMed: 18283224].

[13] Krabuanrat C. Nine Square and Brain Development. BKK: Sinthana Copy Center; 2009.

[14] Harnirattisai T, Thongtawee B, Raetong P. The Effects of a Physical Activity Program for Fall Prevention among Thai Older Adults. Pac Rim Int J Nurs Res. 2015;19(1):4-18.

[15] Ronnarithivichai C, Thaweeboon T, Petchansri S, Sujijantararat R, Boonchau N, Kridiborwon C. The evaluation of physical fitness before and after 9-square-tableaerobic exercise and rubber ring stretching of elders in the health promotion program, Faculty of Nursing, Mahidol University. J Nur Sci. 2009;17(3):68-77.

[16] Hemwong P. The effect of the matrix of nine square training and flexibility on agility. Acad J Inst Phys Ed. 2012;4(1):131-42.

[17] Rikli RE, Jones CJ. Senior Fitness Test Manual. IL. Human Kinetics; 2001.

[18] Cruz-Jentoft AJ, Landi F, Topinkova E, Michel JP. Understanding sarcopenia as a geriatric syndrome. Curr Opin Clin Nutr Metab Care. 2010;13(1):1-7. doi: 10.1097/MCO.0b013e328333c1c1. [PubMed: 19915458].

[19] Mazzeo RS, Tanaka H. Exercise prescription for the elderly: cur- rent recommendations. Sports Med. 2001;31(11):809-18. [PubMed: 11583105].

[20] Iannuzzi-Sucich M, Prestwood KM, Kenny AM. Prevalence of sarcopenia and predictors of skeletal muscle mass in healthy, older men and women. $J$ Gerontol A Biol Sci Med Sci. 2002;57(12):M772-7. [PubMed: 12456735].

[21] Adams KJ, Swank AM, Berning JM, Sevene-Adams PG, Barnard KL, Shimp-Bowerman J. Progressive strength training in sedentary, older African American women. Med Sci Sports Exerc. 2001;33(9):1567-76. [PubMed: 11528347].

[22] Grimby G, Aniansson A, Hedberg M, Henning GB, Grangard U, Kvist $H$. Training can improve muscle strength and endurance in 78- to 84-yr- old men. J Appl Physiol (1985). 1992;73(6):2517-23. [PubMed: 1490965].

[23] Muehlbauer T, Gollhofer A, Granacher U. Associations Between Measures of Balance and Lower-Extremity Muscle Strength/Power in Healthy Individuals Across the Lifespan: A Systematic Review and Meta-Analysis. Sports Med. 2015;45(12):1671-92. doi: 10.1007/s40279- 015-0390-z. [PubMed: 26412212].

[24] Ryushi T, Kumagai K, Hayase H, Abe T, Shibuya K, Ono A. Effect of resistive knee extension training on postural control measures in middle aged and elderly persons. $J$ Physiol Anthropol Appl Human Sci. 2000;19(3):143-9. [PubMed: 10924038]. 
[25] Junprasert S, Toonsiri C, Chala-em T, Choojun N, Kirdnoil P, Songprasert A, et al. Impact of nine-square Thai dancing on elderly people's health. Thai J Nurs Council. 2013;28(4):6880 .

[26] Nelson ME, Rejeski WJ, Blair SN, Duncan PW, Judge JO, King AC, et al. Physical activity and public health in older adults: recommendation from the American College of Sports Medicine and the American Heart Association. Med Sci Sports Exerc. 2007;39(8):1435-45. doi: 10.1249/mss.0b013e3180616aa2. [PubMed: 17762378].

[27] American College of Sports Medicine. ACSM's Guidelines for exercise testing and prescription. NY: Lippincott, William \& Wilkins; 2010.

[28] Hong Y, Li JX, Robinson PD. Balance control, flexibility, and cardiorespiratory fitness among older Tai Chi practitioners. $\mathrm{Br}$ J Sports Med. 2000;34(1):29-34. [PubMed: 10690447].

[29] Binder EF, Birge SJ, Spina R, Ehsani AA, Brown M, Sinacore DR, et al. Peak aerobic power is an important component of physical performance in older women. J Gerontol A Biol Sci Med Sci. 1999;54(7):M353-6. [PubMed: 10462167].

[30] Singh MA. Exercise and aging. Clin Geriatr Med. 2004;20(2):201-21. doi: 10.1016/j.cger.2004.03.003. [PubMed: 15182878].

[31] Singh NA, Clements KM, Fiatarone MA. A randomized controlled trial of progressive resistance training in depressed elders. J Gerontol A Biol Sci Med Sci. 1997;52(1):M27-35. [PubMed: 9008666].

[32] Williams PE, Goldspink G. Longitudinal growth of striated muscle fibers. J Cell Sci. 1971;9(3):751-67. [PubMed: 5148015].

[33] Kottke FJ, Pauley DL, Ptak RA. The rationale for prolonged stretching for correction of shortening of connective tissue. Arch Phys Med Reha- bil. 1966;47(6):345-52. [PubMed: 5940624].

[34] Barnett JG, Holly RG, Ashmore CR. Stretch-induced growth in chicken wing muscles: biochemical and morphological characterization. Am J Physiol. 1980;239(1):C39-46. [PubMed: 6156603].

[35] Herriott MT, Colberg SR, Parson HK, Nunnold T, Vinik AI. Effects of 8 weeks of flexibility and resistance training in older adults with type 2 diabetes. Diabetes Care. 2004;27(12):2988-9. [PubMed: 15562222].

[36] Girouard CK, Hurley BF. Does strength training inhibit gains in range of motion from flexibility training in older adults? Med Sci Sports Ex- erc. 1995;27(10):1444-9. [PubMed: 8531617].

[37] Sousa N, Mendes R, Abrantes C, Sampaio J, Oliveira J. Effective- ness of combined exercise training to improve functional fitness in older adults: A randomized controlled trial. Geriatr Gerontol Int. 2014;14(4):892-8. doi: 10.1111/ggi.12188. [PubMed: 24779956].

[38] Wanderley FA, Silva G, Marques E, Oliveira J, Mota J, Carvalho J. Associations between objectively assessed physical activity levels and fitness and self-reported healthrelated quality of life in community-dwelling older adults. Qual Life Res. 2011;20(9):1371-8. doi: 10.1007/s11136-0119875-x. [PubMed: 21380765]. 